\title{
Cellular Physiology

\section{Adenosine Promotes GATA-2-Regulated p53 Gene Transcription to Induce HepG2 Cell Apoptosis}

\author{
Takahiro Yaguchi ${ }^{1}$, Takashi Nakano ${ }^{2}$, Akinobu Gotoh ${ }^{3}$ and Tomoyuki \\ Nishizaki ${ }^{1}$
}

${ }^{1}$ Division of Bioinformation, Department of Physiology, Hyogo College of Medicine, Nishinomiya, ${ }^{2}$ Department of Thoracic Oncology, Hyogo College of Medicine, Nishinomiya, ${ }^{3}$ Laboratory of Cell and Gene Therapy, Institute for Advanced Medical Sciences, Hyogo College of Medicine, Nishinomiya

\section{Key Words}

Adenosine $\cdot$ GATA-2 $•$ p53 $\cdot$ Apoptosis $\cdot$ HepG2 cell

\begin{abstract}
Background/Aims: In our earlier study, adenosine induced apoptosis in HepG2 human hepatoma cells by tuning of apoptosis-mediator gene transcription. The present study aimed at understanding the regulatory mechanism underlying the apoptosismediator gene transcription under the control of adenosine. Methods: For HepG2 cells with and without knocking-down p53 or GATA-2, cell viability, mitochondrial membrane potentials, caspase activity, and transcriptional activity were monitored, and Western blotting, RT-PCR, electrophoretic mobility shift assay (EMSA), and chromatin immunoprecipitation (ChIP) assay were carried out. Results: Extracellular adenosine upregulated expression of the p53 mRNA and protein in HepG2 human hepatoma cells. Adenosine induced apoptosis, disrupted mitochondrial membrane potentials, and activated caspase- $3,-8$ and -9 in HepG2 cells, and those effects were inhibited by silencing the p53-targetd gene. In the assay of transcriptional activity using full-length p53 gene promoter and 5' deletion mutants combined
\end{abstract}

\section{KARGER}

Fax +41613061234

E-Mail karger@karger.ch

www.karger.com
(C) 2011 S. Karger AG, Basel

$1015-8987 / 11 / 0284-0761 \$ 38.00 / 0$

Accessible online at:

www.karger.com/cpb with the luciferase reporter vector, adenosine enhanced transcriptional activity for full-length p53 gene promoter, that was prevented by deleting from -240 to -146 bp on the promoter. In the EMSA using a ${ }^{32} \mathrm{P}$-labeled DNA probe to detect binding to the putative GATA-2 biding site on the p53 gene promoter, adenosine produced ${ }^{32} \mathrm{P}$-positive signals in nuclear extracts from HepG2 cells. In the Western blot analysis, adenosine increased presence of GATA-2 in nuclear extracts. In the ChIP assay, adenosine increased PCR products for the p53 gene promoter in chromosomal extracts from HepG2 cells, immunoprecipitated using an anti-GATA-2 antibody. Adenosine-induced upregulation of the p53 mRNA expression was suppressed by knocking-down GATA-2. Conclusion: The results of the present study show that p53 is a transcriptional target of GATA-2 and that adenosine upregulates GATA-2-regulated p53 expression, thereby activating caspase- $-3,-8$, and -9 to induce HepG2 cell apoptosis.

Copyright @ 2011 S. Karger AG, Basel

\section{Introduction}

Several avenues of evidence have shown that extracellular adenosine induces apoptosis in a variety of

Prof. Tomoyuki Nishizaki

Division of Bioinformation, Department of Physiology

Hyogo College of Medicine, 1-1 Mukogawa-cho, Nishinomiya 663-8501 (Japan) Tel. +81-798-45-6397, Fax +81-798-45-6649

E-Mail tomoyuki@hyo-med.ac.jp 
cells via intrinsic pathways linked to adenosine uptake into cells and/or extrinsic pathways linked to adenosine receptors. Intracellularly transported adenosine induces apoptosis in GT3-TKB human lung cancer cells by activating AMP-activated protein kinase (AMPK) [1]. Adenosine induces apoptosis in Caco-2 human colonic cancer cells by activating caspase- 3 and -9 via $A_{2 a}$ adenosine receptors linked to $\mathrm{G}_{\mathrm{s}}$ protein [2]. Adenosine, alternatively, induces apoptosis in RCR-1 astrocytoma cells via both the intrinsic and extrinsic pathways each relevant to AMPK activation and $\mathrm{A}_{1}$ adenosine receptors [3]. Additionally, adenosine is shown to induce apoptosis in hepatocellular carcinoma cells as mediated via $\mathrm{A}_{3}$ adenosine receptors [4].

Amazingly, adenosine induces apoptosis in human hepatoma cell lines such as HuH-7 and HepG2 cells by tuning transcription of apoptosis-related genes. For $\mathrm{HuH}-$ 7 human hepatoma cells, intracellularly transported adenosine activates caspase- 8 and the ensuing caspase3 , by downregulating expression of Fas-associated death domain protein (FADD)-like interleukin-1 $\beta$-converting enzyme inhibitory protein (FLIP) [5]. Adenosine downregulates expression of $\mathrm{Bcl}-\mathrm{X}_{\mathrm{L}}$ and inhibitor of apoptosis protein (IAP), to directly inhibit caspase- $3,-7$, and -9 , but otherwise adenosine upregulates expression of DIABLO, an inhibitor of IAPs [6]. Those actions account for adenosine-induced $\mathrm{HuH}-7$ cell apoptosis.

For HepG2 human hepatoma cells, adenosine upregulates expression of mRNAs for tumor necrosis factor (TNF), TNF receptor 1-associated death domain protein (TRADD), TNF related apoptosis-inducing ligand receptor 2 (TRAIL-R2), TRADD/receptor-interacting protein kinase 1 (RIPK1), Fas-associated death domain (FADD), and caspase-9 [7]. TNFR1 is activated by TNF$\alpha$ and forms a complex of TRADD/RIP1/FADD/ procaspase- 8 , to activate caspase- $8[8,9]$. This pathway, accordingly, may account for adenosine-induced HepG2 cell apoptosis. How adenosine regulates apoptosis-related gene transcription in HepG2 cells, however, remains to be explored.

The tumor suppressor protein $\mathrm{p} 53$ is the major senescence- and apoptotic cell death-inducing transcription factor that targets hundreds of genes. p53 executes cancer cell apoptosis via transcription-dependent and -independent pathways. Bcl-2 homology 3 (BH3)only Bcl-2 family members such as Puma and Noxa are transcriptional targets of p53 [10]. For p53-mediated transcription-dependent apoptotic pathway, Puma and Noxa release pro-apoptotic Bax subfamily members such as Bax and Bak from the association with anti-apoptotic
Bcl-2 subfamily members such as Bcl-2, Bcl- $\mathrm{X}_{\mathrm{L}}$, and Mcl1 , thereby disrupting mitochondrial membrane potentials, to allow cytochrome $\mathrm{c}$ efflux from the mitochondria into the cytosol, which triggers activation of caspase- 9 and the effector caspase- 3 to induce apoptosis $[11,12]$. Puma and Noxa, alternatively, induces apoptosis by antagonizing Bcl-2 subfamily members [13]. For p53-mediated transcription-independent apoptotic pathway, p53 stimulates release of apoptogenic factors from the mitochondria, that include cytochrome $\mathrm{c}$ and Smac/ DIABLO [14-17]. Cytochrome $\mathrm{c}$ forms the apoptosome that consists of the adapter protein Apaf-1 and caspase9, to activate caspase-9 and the ensuing caspase-3 [1417]. Smac/DIABLO activates caspase-3 through repression of IAPs [14-17].

GATA is a zinc-finger transcription factor, and the family consists of six proteins such as GATA-1, $-2,-3,-4$, -5 , and -6 , that engage in a development/cell type-specific manner. GATA-1, GATA-2, and GATA-3 play multiple vital roles in hematopoiesis in many cell lineages. GATA1 and GATA-2 participate in lineage-specific transcription factor networks essential for proper differentiation of erythroid cells, that regulate erythroid gene expression, and GATA-1 and GATA-2 genes by themselves are also regulated by multiple transcription factors, including their own products GATA-1 and GATA-2 [18]. GATA-2 is required for genesis and/or function of hematopoietic stem cells, while GATA-1 drives differentiation of hematopoietic progenitors into a subset of the blood cell lineages [19]. GATA-1 directly represses GATA-2 gene transcription, thereby displacing GATA-2 from chromatin, a process termed a GATA switch [19]. GATA-3 serves as a master regulator of T-helper 2 cell differentiation in mature $\mathrm{CD}^{+} \mathrm{T}$ cells and is required at each stage of Tcell development [20]. Interestingly, GATA-3 still regulates normal cell development and tumor differentiation in non-hematopoietic cells including mammary cells [21].

An interaction between GATA family and $\mathrm{p} 53$ is not fully understood. For erythroid cells, GATA-1 inhibits activation of $\mathrm{p} 53$ gene promoter by binding to the GATA1-binding site [22]. Multipotential hematopoietic progenitors lacking GATA-2 poorly proliferate and generate small colonies with extensive cell death, and the effect is restored by additionally deleting p53, suggesting that GATA-2 proliferates and protects early hematopoietic cells by inhibiting p53 function [23].

The present study focused upon GATA-2 and investigated GATA-2-regulated p53 gene transcription, responsible for adenosine-induced HepG2 cell apoptosis.

Yaguchi/Nakano/Gotoh/Nishizaki 


\section{Materials and Methods}

\section{Cell culture}

HepG2 cells, obtained from RIKEN cell bank (Ibaraki, Japan), were cultured in minimum essential medium supplemented with $10 \%(\mathrm{v} / \mathrm{v})$ heat-inactivated fetal bovine serum $(\mathrm{FBS}), 1 \%(\mathrm{w} / \mathrm{v})$ non-essential amino acids, penicillin (final concentration, $100 \mathrm{U} / \mathrm{ml}$ ), and streptomycin (final concentration, $0.1 \mathrm{mg} / \mathrm{ml}$ ), in a humidified atmosphere of $5 \%$ $\mathrm{CO}_{2}$ and $95 \%$ air at $37{ }^{\circ} \mathrm{C}$. ACHN human renal cell adenocarcinoma cells, kindly provided from the Cell Resource Center for Biomedical Research Institute of Development, Aging and Cancer, Tohoku University (Sendai, Japan), were cultured in Dulbecco's Modified Eagles Medium. Each medium was supplemented with $10 \%(\mathrm{v} / \mathrm{v})$ heat-inactivated FBS, penicillin (final concentration, $100 \mathrm{U} / \mathrm{ml}$ ), and streptomycin (final concentration, $0.1 \mathrm{mg} / \mathrm{ml}$ ), in a humidified atmosphere of $5 \% \mathrm{CO}_{2}$ and $95 \%$ air at $37{ }^{\circ} \mathrm{C}$.

\section{Assay of cell viability}

Cell viability was assayed by the method using 3-(4,5dimethyl-2-thiazolyl)-2,5-diphenyl- 2H-tetrazolium bromide (MTT) as described previously [2]. MTT-reactive cells were quantified at an absorbance of $570 \mathrm{~nm}$ using a micro-plate reader (SPECTRAmax PLUS384, Molecular Devices, Sunnyvale, USA), and percentage of independent basal levels was calculated.

\section{Assay of mitochondrial membrane potentials}

Mitochondrial membrane potentials were measured using a DePsipherTM kit. HuH-7 cells were untreated and treated with adenosine $(3 \mathrm{mM})$ for $48 \mathrm{~h}$. After washing with cold phosphate-buffered saline, cells were incubated in a DePsipherTM solution at $37{ }^{\circ} \mathrm{C}$ for $20 \mathrm{~min}$. Then, cells were washed with $1 \mathrm{ml}$ of a reaction buffer containing a stabilizer solution. The fluorescent signals were observed with a laser scanning microscopes (LSM 510, Carl Zeiss Co., Ltd, Germany) equipped with an epifluorescence device using a fluorescein long-pass filter (fluorescein and rhodamine) at an absorbance of $590 \mathrm{~nm}$ for red aggregations and at an absorbance of $530 \mathrm{~nm}$ for green aggregations.

\section{Assay of caspase activity}

Activation of caspase-3, -8 , and -9 was enzymatically measured using a caspase fluorometric assay kit (Ac-Asp-GluVal-Asp-MCA for a caspase-3 substrate peptide; Ac-Ile-GluThr-Asp-MCA for a caspase- 8 substrate peptide; and Ac-LeuGlu-His-Asp-MCA for a caspase- 9 substrate peptide) as previously described [2]. After 24-h treatment with adenosine (3 mM), HepG2 cells were harvested, pelleted, and frozen on dry ice. The pellet was resuspended in a cell lysis buffer and incubated on ice for $10 \mathrm{~min}$, and the lysates were centrifuged at $15000 \mathrm{x} \mathrm{g}$ for $10 \mathrm{~min}$ at $4{ }^{\circ} \mathrm{C}$. A total of $50 \mu \mathrm{g}$ of cell lysates was incubated with $5 \mu \mathrm{l}$ of $1 \mathrm{mM}$ stock of the respective fluorescently labeled tetrapeptide at $37{ }^{\circ} \mathrm{C}$ for $2 \mathrm{~h}$. The fluorescence was measured at an excitation of $400 \mathrm{~nm}$ and at an emission of $505 \mathrm{~nm}$ with a fluorometer (Fluorescence Spectrometer, F-4500, HITACHI, Tokyo, Japan).

GATA-2-Regulated p53 Gene Transcription
Knocking-down p53 and GATA-2

The small interfering RNA (siRNA) silencing the p53targeted gene (p53 siRNA) was purchased from Santa Cruz Biotechnology (Santa Cruz, CA, USA). We constructed the siRNA silencing the GATA-2-targeted gene (GATA-2 siRNA): sense, 5'-GCG CAC AAC UAC AUG GAA CTT-3' and antisense, 5'-GUU CCA UGU AGU UGU GCG CTT-3'; sense, 5'CGG AAG AUG UCC AAC AAG UTT-3' and anti-sense, 5'ACU UGU UGG ACA UCU UCC GTT-3'; and sense, 5'-AGG AAA AAG GAU UAG GCA ATT-3' and anti-sense, 5'-UUG CCU AAU CCU UUU UCC UTT-3' (Cosmo Bio, Co. Ltd., Tokyo, Japan). The p53 siRNA, the GATA-2 siRNA, and the negative control siRNA (NC siRNA) were transfected using a Nucleofector II device (Amaxa biosystems, Cologne, Germany).

\section{Extraction of nuclear and cytosolic components}

HepG 2 cells were suspended in a buffer A [10 mM HEPES, $10 \mathrm{mM} \mathrm{KCl}, 0.1 \mathrm{mM}$ EDTA, $0.1 \mathrm{mM}$ EGTA, $1 \mathrm{mM}$ DTT, and 1\% (v/v) protease inhibitor cocktail, $\mathrm{pH} 7.4$ ] and lysed with $10 \%$ (v/v) NonidetP-40. After $15,000 \times \mathrm{g}$ centrifugation at $4{ }^{\circ} \mathrm{C}$ for 5 min, the pellet was resuspended in ice-cold buffer B $[20 \mathrm{mM}$ HEPES, 0.4 M NaCl, 1 mM EDTA, 1 mM EGTA, 1 mM DTT, 1\% $(\mathrm{v} / \mathrm{v})$ protease cocktail inhibitor, $\mathrm{pH}$ 7.9] as a nuclear component and the supernatant was collected as a cytosolic component.

\section{Western blotting}

Lysates from total HepG2 cells or nuclear components were subjected to $10 \%(\mathrm{v} / \mathrm{v})$ sodium dodecylsulfate polyacrrylamide gel electrophoresis (SDS-PAGE) and transferred to polyvinylidene difluoride membranes. Blotting membranes were blocked TBST [150 mM NaCl, 0.1\% (v/v) Tween 20, and $20 \mathrm{mM}$ Tris] containing 5\% (v/v) bovine serum albumin and reacted with antibodies against p53 (Calbiochem, CA, USA), and GATA-2 (Santacruz, CA, USA), $\beta$-actin (SIGMA-Aldrich, MO, USA), followed by an HRP-conjugated anti mouse or rabbit $\mathrm{IgG}$ antibody. Immunoreactivity was detected with an ECL kit (GE healthcare, NJ, USA) and visualized with an Image Gauge software (FUJIFILM, Tokyo, Japan).

Reverse transcription-polymerase chain reaction ( $R T$ PCR)

Total RNAs were purified from cells by an acid/guanidine/ thiocyanate/chloroform extraction method using a SepasolRNA I Super kit. After purification, total RNAs were treated with RNase free-DNase I ( 2 unit) at $37^{\circ} \mathrm{C}$ for $30 \mathrm{~min}$ to remove genomic DNAs, and $10 \mu \mathrm{g}$ of RNAs were resuspended in water. Then, oligo dT primers, dNTPs, 5 x First Strand buffer, and SuperScripit III RNase H-Reverse Transcriptase were added to the RNA solution and incubated at $65^{\circ} \mathrm{C}$ for $5 \mathrm{~min}$ followed by $56^{\circ} \mathrm{C}$ for $60 \mathrm{~min}, 58^{\circ} \mathrm{C}$ for $60 \mathrm{~min}, 85^{\circ} \mathrm{C}$ for $5 \mathrm{~min}$ to synthesize the first strand cDNA. Subsequently, $1 \mu 1$ of the reaction solution was diluted with water and mixed with $10 \times \mathrm{PCR}$ reaction buffer, dNTPs, $\mathrm{MgCl}_{2}$, oligonucleotide, dimethylsulfoxide (final concentration, $5 \% \mathrm{v} / \mathrm{v}$ ) and 1 unit of Taq polymerase (Fermentas, St. Leon-Roth, Germany)(final volume, $20 \mu \mathrm{l}$ ). RTPCR was carried out with a GeneAmp PCR system model 9600 DNA thermal cycler (Applied Biosystems, Indianapolis, USA) programmed as follows: the first one step, $94^{\circ} \mathrm{C}$ for $4 \mathrm{~min}$ and 
the ensuing 30 cycles, $94^{\circ} \mathrm{C}$ for $1 \mathrm{~s}, 62^{\circ} \mathrm{C}$ for $15 \mathrm{~s}$, and $72{ }^{\circ} \mathrm{C}$ for $30 \mathrm{~s}$. The primers used here were as follows: sense, 5'-GCC ATC TAC AAG CAG TCA CAG CAC AT-3' and anti-sense, 5'GGC ACAAAC ACG CAC CTC AAA GC-3' for p53; sense, 5'GAC GGA GAG CAT GAA GAT GGAAAG TGG C-3' and antisense, 5'-GAG GCC ACA GGC ATT GCA CAG GTA GT-3' for GAT A-2; and sense, 5'-GAC TTC AAC AGC GAC ACC CAC TCC-3' and anti-sense, 5'-AGG TCC ACC ACC CTG TTG CTG TAG - 3' for GAPDH. PCR products were stained with ethidium bromide and visualized by $2 \%(\mathrm{v} / \mathrm{v})$ agarose electrophoresis.

\section{Assay of transcriptional activity}

The full length of the human $\mathrm{p} 53$ gene promoter pp53-pI $(-532$ to +1$)$ (forward, 5'-CTG CTA GCG GGA GAA AAC GTT AGG GTG TGG-3'; reverse, 5'-AGG CTA GCC CAA TCC AGG GAA GCG TGT C-3') and 5' deletion mutants such as pp53-pII $(-240$ to +1$)$ (forward, 5'-CTG CTA GCG CGG ATT ACT TGC CCT TAC TTG-3'; reverse, 5'-AGG CTA GCC CAA TCC AGG GAA GCG T GTC-3') and pp53-pIII (-146 to +1)(forward, 5'CTG CTA GCT GCT CAA GAC TGG CGC TAAAAG-3'; reverse, 5'-AGG CTA GCC CAA TCC AGG GAA GCG TGT C-3') were combined with the luciferase reporter vector pGL4.12 (Promega, WI, USA). pp53-pI, pp53-pII, or pp53-pIII was transfected into HepG2 cells using a lipofectamine, and pGL4.73 vector (Promega) was co-transfected as an internal control. Cells were treated and untreated with adenosine $6 \mathrm{~h}$ after transfection and transcriptional activity was quantified by monitoring luciferase luminescent intensities with a luminometer (Berthold, Tokyo, Japan).

\section{Electrophoretic mobility shift assay (EMSA)}

To construct a ${ }^{32} \mathrm{P}$-labeled DNA probe, the DNA element (GCG GAT TAC T) contained in the putative GATA-2 biding site on the p53 gene promoter (5'-GCA GGC GGA TTA CTT GCC CTT A- 3') was incubated in a reaction medium $(6.6 \mathrm{mM}$ Tris- $\mathrm{HCl}, 50 \mathrm{mM} \mathrm{NaCl}, 6.6 \mathrm{mM} \mathrm{MgCl}, 0.5 \mathrm{mM} \mathrm{dGTP}, 0.5 \mathrm{mM}$ dTTP, $1 \mathrm{mM}$ dithiothreitol, pH7.4) containing $200 \mathrm{ng}$ of DNA, 2 $\mu \mathrm{l}$ of $\left[{ }^{32} \mathrm{P}\right] \mathrm{dCTP}$, and 1 unit of klenow fragment at $37{ }^{\circ} \mathrm{C}$ for 20 min, and the DNA probe was collected with a Sephadex G-50 column. Nuclear extracts from HepG2 cells were reacted with the ${ }^{32} \mathrm{P}$-labeled DNA probe in a binding buffer $[20 \mathrm{mM}$ HEPES$\mathrm{NaOH}, 80 \mathrm{mM} \mathrm{NaCl}, 0.3 \mathrm{mM}$ EDTA, $0.2 \mathrm{mM}$ EGTA, $0.2 \mathrm{mM}$ phenylmethanesulfonyl fluoride, $10 \%(\mathrm{v} / \mathrm{v})$ glycerol, $2 \mu \mathrm{g}$ of poly(dI-dC), $\mathrm{pH} 7.9]$ at $25^{\circ} \mathrm{C}$ for $15 \mathrm{~min}$. DNA-protein complexes were separated by an electrophoresis on $4 \%(\mathrm{v} / \mathrm{v})$ polyacrylamide gel.

Chromatin immunoprecipitation (ChIP) assay

Nuclear components extracted from HepG2 cells were immunoprecipitated using an anti-GATA-2 antibody (SANTA CRUZ, CA, USA). DNAs in the immunoprecipitants were extracted with phenol/chloroform and precipitated with ethanol after treatment with proteinase $\mathrm{K}$ at $45^{\circ} \mathrm{C}$ for $1 \mathrm{~h}$, followed by PCR using a primer to detect the p53 gene promoter (sense, 5'GCG GAT TAC TTG CCC TTA CTT G-3' and anti-sense, 5'CCA ATC CAG GGA AGC GTG TC-3'). PCR products were separated by an electrophoresis on $2 \%(\mathrm{v} / \mathrm{v})$ agarose gel, stained with ethidium bromide, and analyzed and NIH Image.

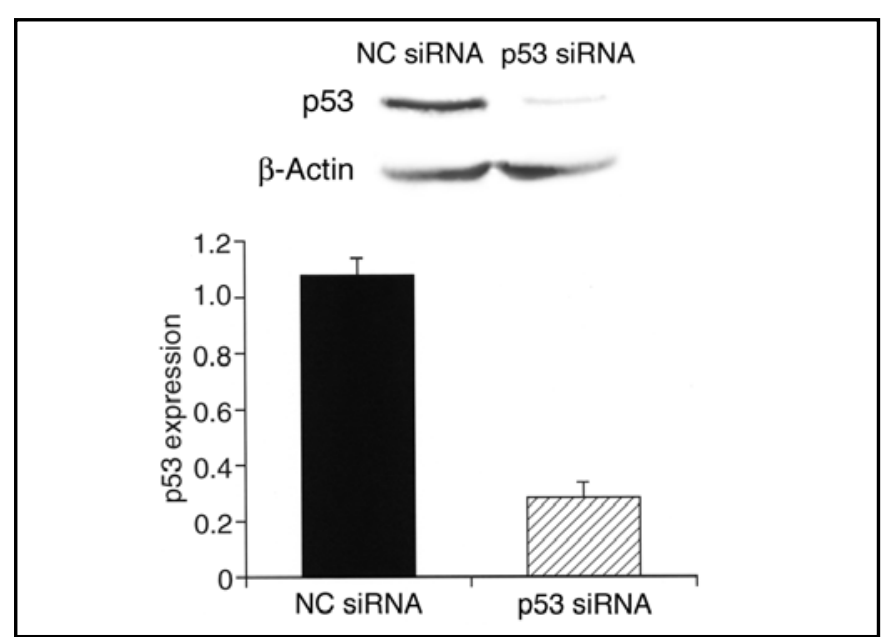

Fig. 1. The p53 siRNA suppresses p53 expression in HepG2 cells. Western blotting using antibodies against p53 and $\beta$ actin was carried out in HepG2 cells transfected with the NC siRNA or the p53 siRNA. p53 immunoreactive intensities were normalized by respective $\beta$-actin immunoreactive intensities. In the graph, each column represents the mean ( \pm SEM) normalized $\mathrm{p} 53$ expression ( $\mathrm{n}=3$ independent experiments).

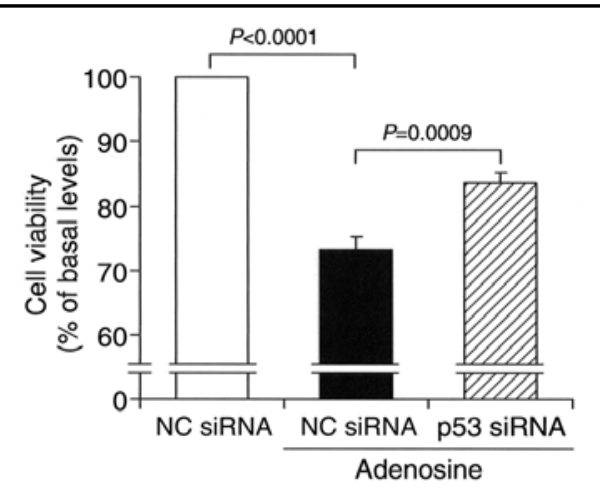

Fig. 2. Adenosine induces HepG2 cell death in a p53-dependent manner. HepG2 cells transfected with the NC siRNA or the p53 siRNA were treated with adenosine $(3 \mathrm{mM})$ for $24 \mathrm{~h}$ followed by MTT assay. In the graph, each column represents the mean ( \pm SEM) percentage of basal levels (MTT intensities for cells untreated with adenosine) ( $\mathrm{n}=12-14$ independent experiments). $P$ values, unpaired $t$-test.

\section{Statistical analysis}

Statistical analysis was carried out using unpaired $t$-test and analysis of variance (ANOVA).

\section{Results}

Extracellular adenosine induces HepG2 cell apoptosis in a p53-dependent manner

We initially examined whether $\mathrm{p} 53$ participates in adenosine-induced HepG2 cell apoptosis. Expression of 


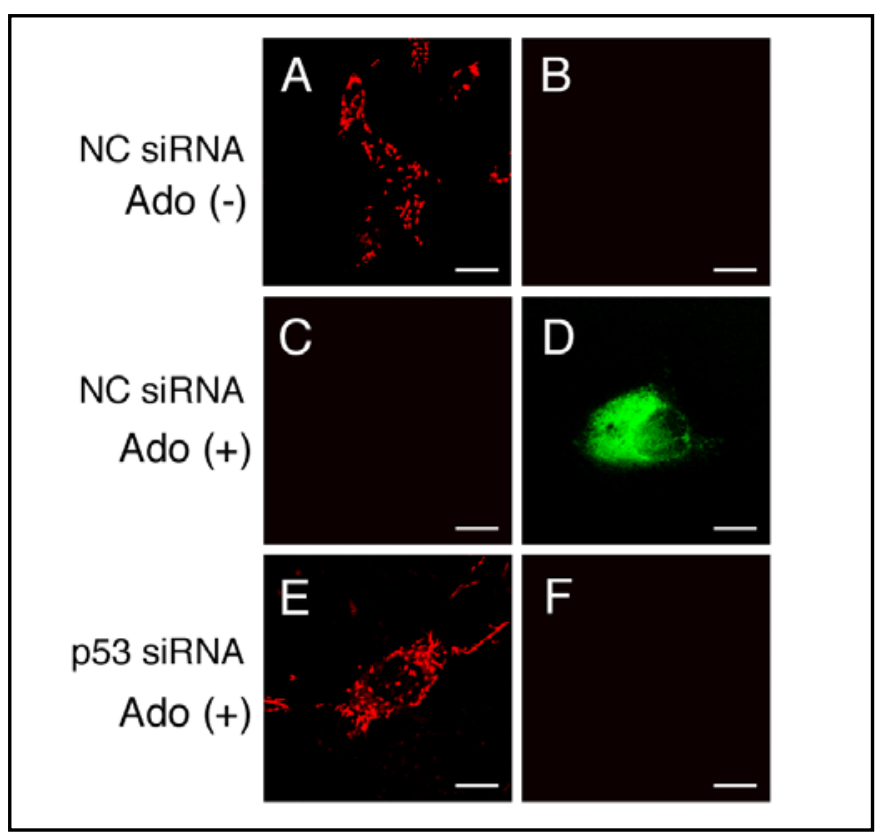

Fig. 3. Adenosine disrupts mitochondrial membrane potentials in a p53-dependent manner. HepG2 cells transfected with the NC siRNA or the p53 siRNA were untreated [Ado (-)] and treated with adenosine $(3 \mathrm{mM})$ [Ado $(+)$ ] for $24 \mathrm{~h}$, and then, mitochondrial membrane potentials were assayed using a DePsipherTM kit. Orange-red (A,C,E) and green fluorescent signals $(\mathrm{B}, \mathrm{D}, \mathrm{F})$ were detected at an absorbance of 590 and 530 $\mathrm{nm}$, respectively. Scale bars, $10 \mu \mathrm{m}$. Note that a similar result was obtained with 4 independent experiments.

p53 protein in HepG2 cells was clearly suppressed by transfecting the p53 siRNA (Fig. 1), indicating p53 knockdown. For cells transfected with the NC siRNA, 24-h treatment with adenosine $(3 \mathrm{mM})$ reduced HepG2 cell viability to approximately $70 \%$ of basal levels, and the effect was significantly inhibited by silencing the $\mathrm{p} 53$ gene (Fig. 2), suggesting the implication of p53 in adenosineinduced HepG2 cell apoptosis.

We next monitored mitochondrial membrane potentials using DePsipherTM. DePsipherTM, a mitochondrial activity marker, has the properties of aggregating upon membrane polarization forming an orange-red fluorescent compound. If the potential is disturbed, the dye has no access to the transmembrane space and remains in or reverts to its green monomeric form. For cells transfected with the NC siRNA before adenosine treatment, the mitochondria exhibited orangered fluorescent signals at an absorbance of $590 \mathrm{~nm}$ (Fig. $3 \mathrm{~A}$ ) and no accumulation of green fluorescent signals at an absorbance of $530 \mathrm{~nm}$ (Fig. 3B). Treatment with adenosine $(3 \mathrm{mM})$ for $24 \mathrm{~h}$ accumulated green fluorescent

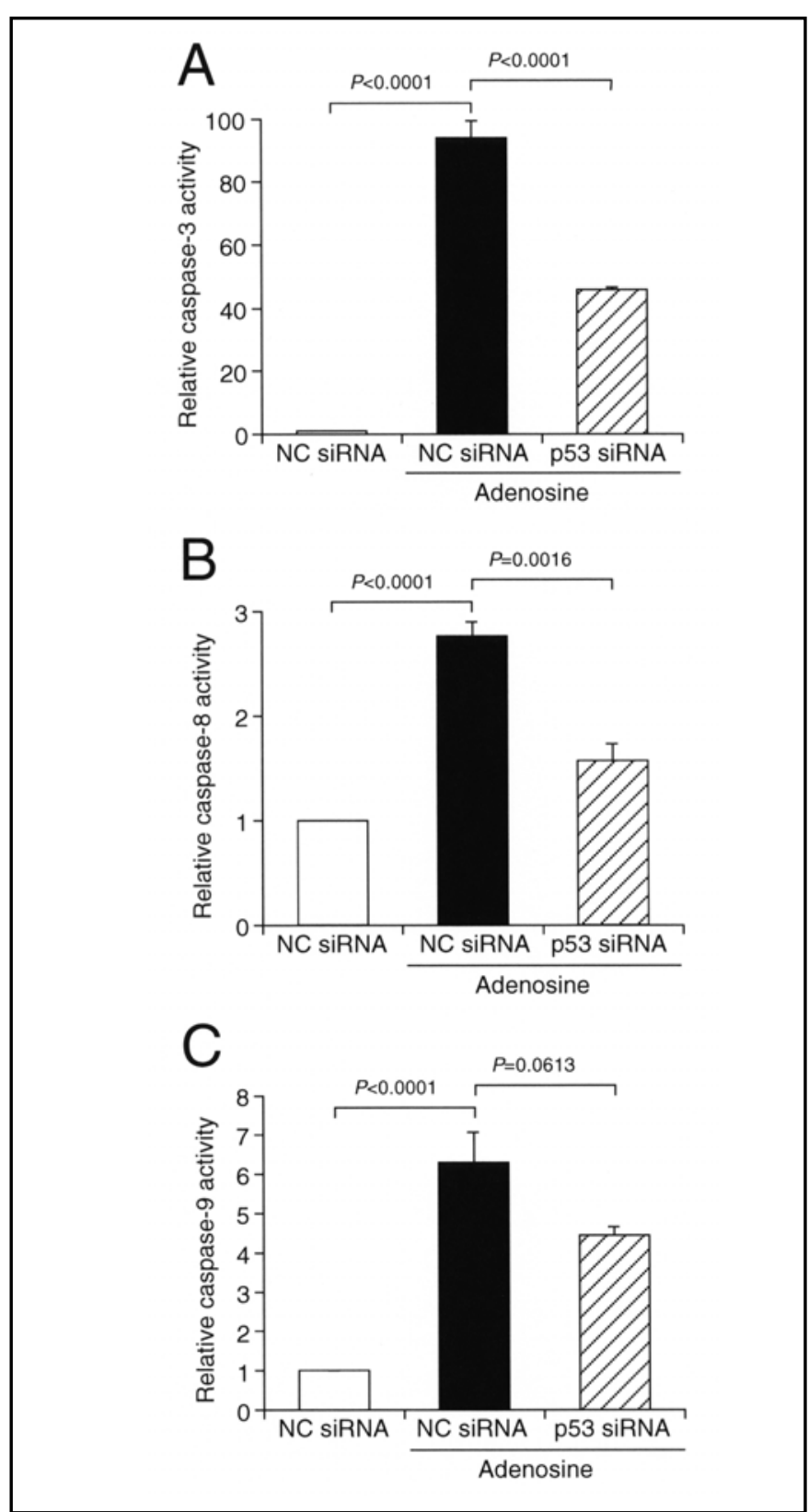

Fig. 4. Adenosine activates caspase-3, -8, and -9. After 24-h treatment with adenosine $(3 \mathrm{mM})$, activities of caspase-3 (A), 8 (B), and -9 (C) were assayed in HepG2 cells transfected with the NC siRNA or the p53 siRNA. In the graphs, each column represents the mean $( \pm$ SEM) ratio against basal caspase activities (before adenosine treatment) $(n=4$ independent experiments). $P$ values, unpaired $t$-test.

signals (Fig. 3D) without orange-red fluorescent signals (Fig. 3C), but the effect was abolished by silencing the p53-targeted gene; accumulation of orange-red fluorescent signals (Fig. 3E) without green fluorescent signals (Fig. 3F). This accounts for adenosine-induced p53-dependent disruption of mitochondrial membrane potentials. 
Fig. 5. Adenosine upregulates p53 expression in HepG2 cells. HepG2 cells were treated with adenosine $(3 \mathrm{mM})$ for periods of time as indicated. (A) RT-PCR. PCR products for the p53 mRNA were normalized by those for the GAPDH mRNA. In the graph, each column represents the mean ( \pm SEM) relative expression of the p53 mRNA against the GAPDH mRNA ( $\mathrm{n}=3$ independent experiments). (B) Western blotting. p53 immunoreactive intensities were normalized by respective $\beta$-actin immunoreactive intensities. In the graph, each column represents the mean $( \pm$ SEM) ratio against basal normalized immunoreactive intensities at $0 \mathrm{~h}$ for cells untreated with adenosine $(n=6$ independent experiments).

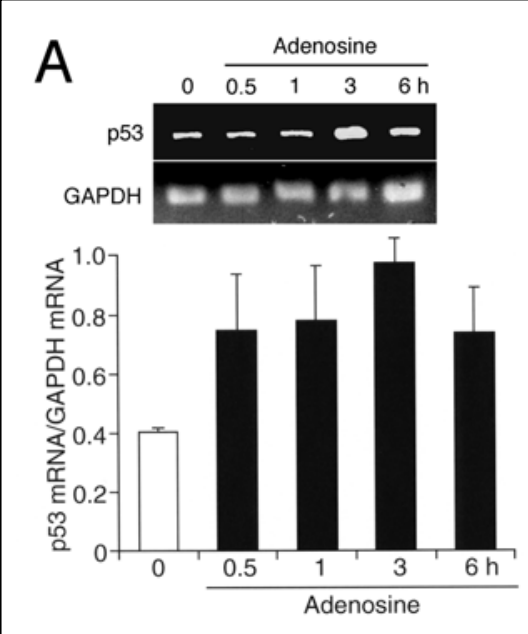

B
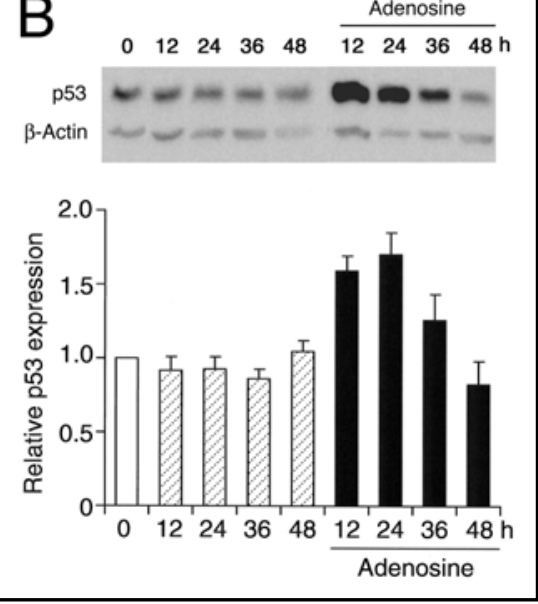

Fig. 6. Adenosine enhances p53 gene transcription by activating the promoter region from -240 to $-146 \mathrm{bp}$. HepG2 cells transfected with the reporter plasmids pp53-pI $(-532$ to +1$)$, pp53pII $(-240$ to +1$)$, or pp53-pIII $(-146$ to +1$)$ were untreated and treated with adenosine (Ado) $(3 \mathrm{mM})$ for $24 \mathrm{~h}$, and then, luciferase assay was carried out. In the graph, each column represents the mean $( \pm$ SEM) percentage of control levels (luciferase luminescent intensities for cells transfected with pp53-pI without adenosine treatment $)(n=6$ independent experiments). $\mathrm{P}$ values, unpaired $t$ test.

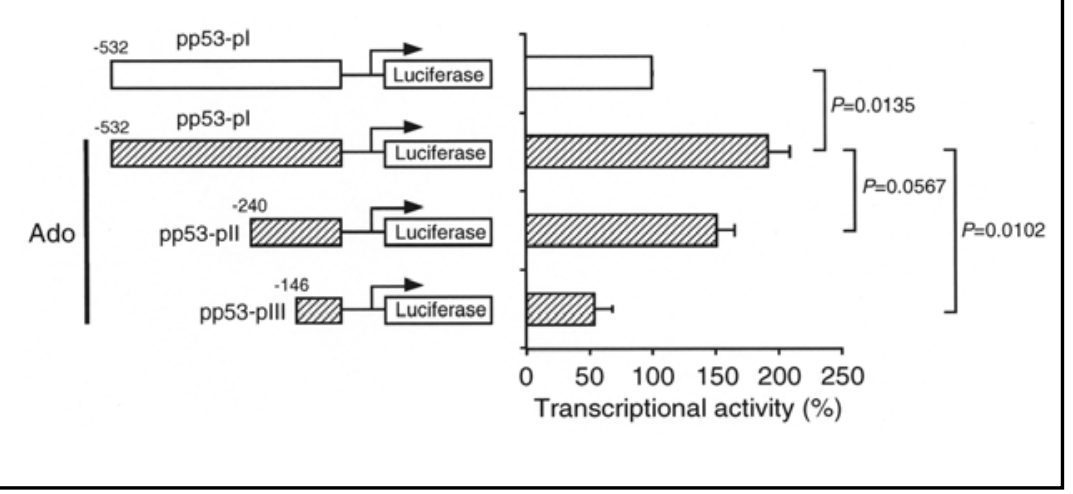

To see the role of p53 in adenosine-induced caspase activation, we enzymatically assayed activities of caspase3, -8 , and -9 in HepG2. Treatment with adenosine ( $3 \mathrm{mM})$ for $24 \mathrm{~h}$ significantly activated caspase- $3,-8$, and -9 for cells transfected with the NC siRNA, with huge activation of caspase-3 (Fig. 4A, B, C). The caspase activation was attenuated by silencing the $\mathrm{p} 53$-targeted gene, significantly for caspase- 3 and -8 activation and not significantly for caspase- 9 activation (Fig. 4A, B, C). This indicates that adenosine activates caspase- 3 and -8 , in part caspase- 9 , in a p53-dependent manner.

Taken together, these results suggest that adenosine activates caspase- 8 and in part caspase- 9 in association with mitochondrial damage and in turn, the effector caspase-3 in a p53-dependent manner, leading to HepG2 cell apoptosis.

Adenosine enhances p53 gene transcription through GATA-2 binding to the promoter region from -240 to -146

Our next attempt was to explore the effect of adenosine on p53 gene transcription in HepG2 cells. In the RT-PCR analysis, adenosine $(3 \mathrm{mM})$ upregulates expression of the p53 mRNA in a bell-shaped treatment time (0.5-6 h)-dependent manner, reaching a peak at $3 \mathrm{~h}$ (Fig. 5A). In the Western blot analysis, adenosine (3 mM) increased expression of $\mathrm{p} 53$ protein in a bell-shaped treatment time (12-48 h)-dependent manner, with a maximum (1.7 times of basal levels) at 24-h (Fig. 5B). Adenosine, thus, appears to govern $\mathrm{p} 53$ gene transcription, causing an increase in the expression of p53 protein, in HepG2 cells.

In the assay of p53 gene transcriptional activity in HepG 2 cells, adenosine $(3 \mathrm{mM})$ significantly enhanced the p53 gene transcriptional activity for cells transfected with the reporter plasmid containing the full-length $\mathrm{p} 53$ gene promoter (Fig. 6). The adenosine effect was inhibited by deleting from -532 to -240 on the $\mathrm{p} 53$ gene promoter, and more marked inhibition was obtained with deleting from -240 to -146 (Fig. 6). This implies that adenosine stimulates $\mathrm{p} 53$ gene transcription by activating the $\mathrm{p} 53$ promoter region from -240 to -146 .

Then, we asked the question as to how adenosine regulates the p53 gene transcription. To address this question, we searched possible candidates that could bind to the $\mathrm{p} 53$ gene promoter region from -240 to -146 using

Yaguchi/Nakano/Gotoh/Nishizaki 


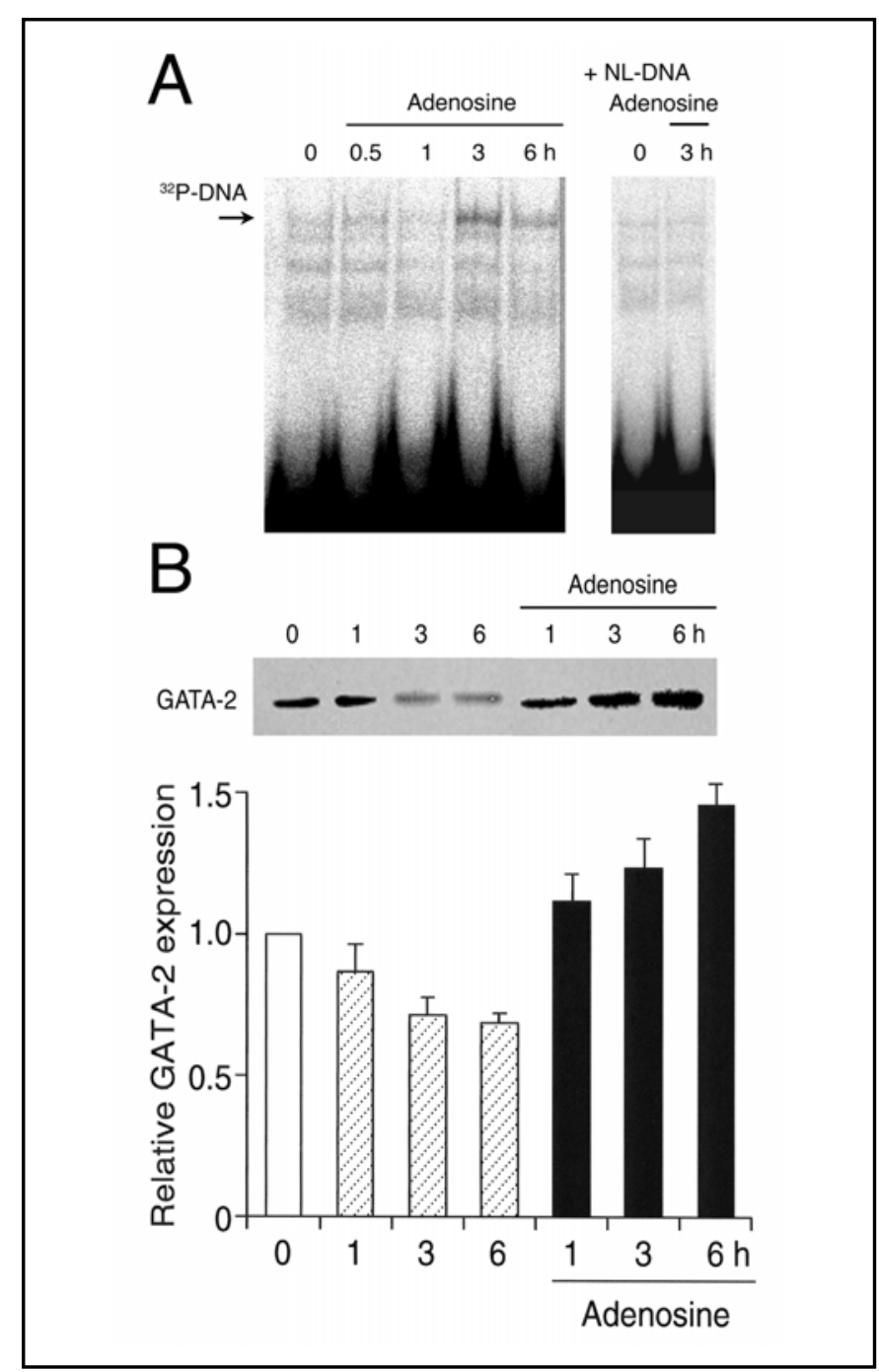

Fig. 7. Adenosine promotes GATA-2 translocation into the nucleus and binding to the putative GATA-2 binding site on the p53 gene promoter. Nuclear extracts were prepared from HepG2 cells untreated and treated with adenosine $(3 \mathrm{mM})$ for periods of time as indicated. (A) EMSA was carried out in nuclear extracts using ${ }^{32} \mathrm{P}$-DNA probe to detect binding to the putative GATA-2 binding site on the $\mathrm{p} 53$ gene promoter in the absence and presence of non-labeled DNA probe $(1 \mu \mathrm{g})(\mathrm{NL}-\mathrm{DNA})$. Note that similar results were obtained with 4 independent experiments. (B) Western blotting was carried out in nuclear extracts using an anti-GATA-2 antibody. In the graph, each column represents the mean $( \pm$ SEM) ratio against basal immunoreactive intensities at $0 \mathrm{~h}$ for cells untreated with adenosine ( $\mathrm{n}=3$ independent experiments).

a TFSEARCH, and the most plausible hit was GATA-2. $\mathrm{We}$, therefore, constructed a ${ }^{32} \mathrm{P}$-labeled DNA probe, that can detect GATA-2 binding to the $\mathrm{p} 53$ gene promoter, and carried out EMSA. Adenosine $(3 \mathrm{mM})$ produced signals reactive to the ${ }^{32} \mathrm{P}$-labeled DNA probe in nuclear extracts from HepG2 cells, the signal intensity reaching a maximum at 3-h treatment, and the signals were neutra-

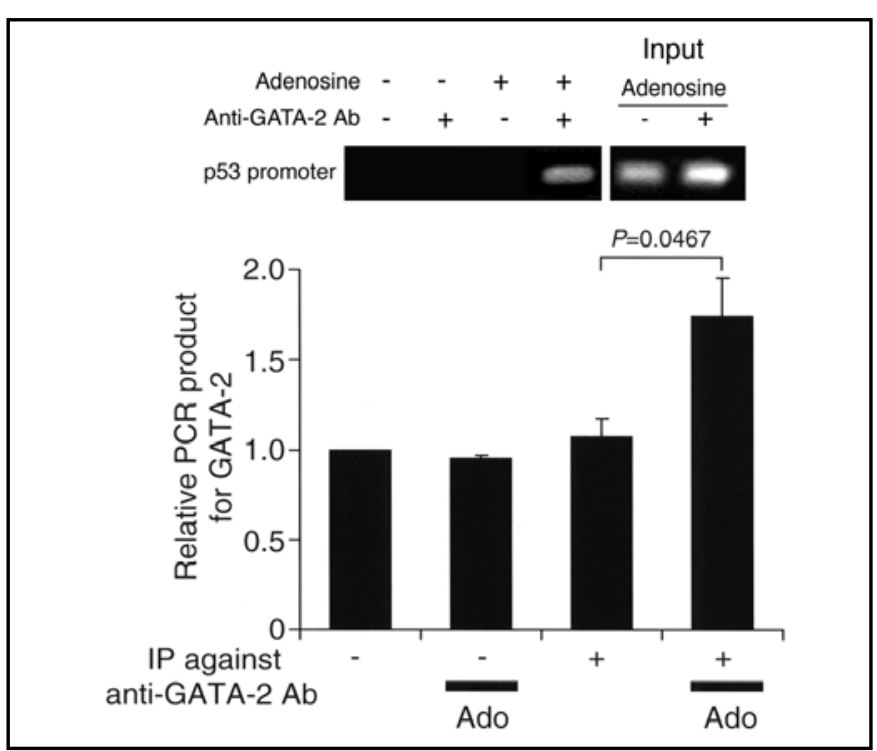

Fig. 8. Adenosine stimulates GATA-2 binding to the $\mathrm{p} 53$ gene promoter. Nuclear components were extracted from HepG2 cells untreated and treated with adenosine $(3 \mathrm{mM})$ for $24 \mathrm{~h}$ and subjected to non-immunoprecipitation and immunoprecipitation (IP) using an anti-GATA-2 antibody (Ab). For another preparation, cells untreated and treated with adenosine $(3 \mathrm{mM})$ for $24 \mathrm{~h}$ were lysed. PCR for the $\mathrm{p} 53$ gene promoter was carried out in the nuclear extracts and cell lysates (Input). In the graph, each column represents the mean ( \pm SEM) ratio against basal PCR products for nuclear extracts from cells untreated with adenosine without immunoprecipitation using an anti-GATA-2 antibody ( $\mathrm{n}=3$ independent experiments). $P$ value, unpaired $t$-test.

lized by adding non-labeled DNA probe (Fig. 7). This suggests that adenosine promotes GATA-2 binding to the p53 gene promoter.

For nuclear extracts from HepG2 cells, adenosine $(3 \mathrm{mM})$ increased immunoreactive signals against an antiGATA-2 antibody in a treatment time (1-6 h)-dependent manner (Fig. 7). This indicates that adenosine accumulates GATA-2 in the nucleus, possibly due to GATA-2 binding to the $\mathrm{p} 53$ gene promoter.

To obtain further evidence for GATA-2 binding to the p53 gene promoter, we carried out ChIP assay. Nuclear extracts from HepG2 cells were immunoprecipitated using an anti-GATA-2 antibody followed by PCR using a primer to detect the p53 gene promoter. For immunoprecipitated samples, adenosine $(3 \mathrm{mM})$ significantly increased PCR products for the p53 gene promoter (Fig. 8). Notably, such adenosine effect was not obtained with non-immunoprecipitated samples (Fig. 8 ). This confirms that adenosine promotes GATA-2 binding to the $\mathrm{p} 53$ gene promoter.

We finally examined whether adenosine upregulates p53 mRNA expression by stimulating GATA-2 binding to 
Fig. 9. Adenosine promotes p53 gene transcription in a GATA-2-dependent manner. (A) HepG2 cells were transfected with the NC siRNA or the GATA-2 siRNA, and $24 \mathrm{~h}$ later RT-PCR was carried out. PCR products for the GATA-2 mRNA were normalized by those for the GAPDH mRNA. In the graph, each column represents the mean $( \pm$ SEM) relative expression of the GATA-2 mRNA against the GAPDH mRNA ( $\mathrm{n}=4$ independent experiments). $P$ value, unpaired $t$-test. (B) HepG2 cells transfected with the NC siRNA or the GATA-2 siRNA were treated with adenosine $(3 \mathrm{mM})$ for periods of time as indicated, followed by RT-PCR. In the RT-PCR analysis, PCR products for the p53 mRNA were normalized by those for the GAPDH mRNA. In the graphs, each column represents the mean $( \pm$ SEM) relative expression of the p53 mRNA against the GAPDH mRNA ( $n=4$ independent experiments). (C) ACHN cells were transfected with the NC siRNA or the GATA-2 siRNA, and $24 \mathrm{~h}$ later RT-PCR was carried out. PCR products for the GATA-2 mRNA were normalized by those for the

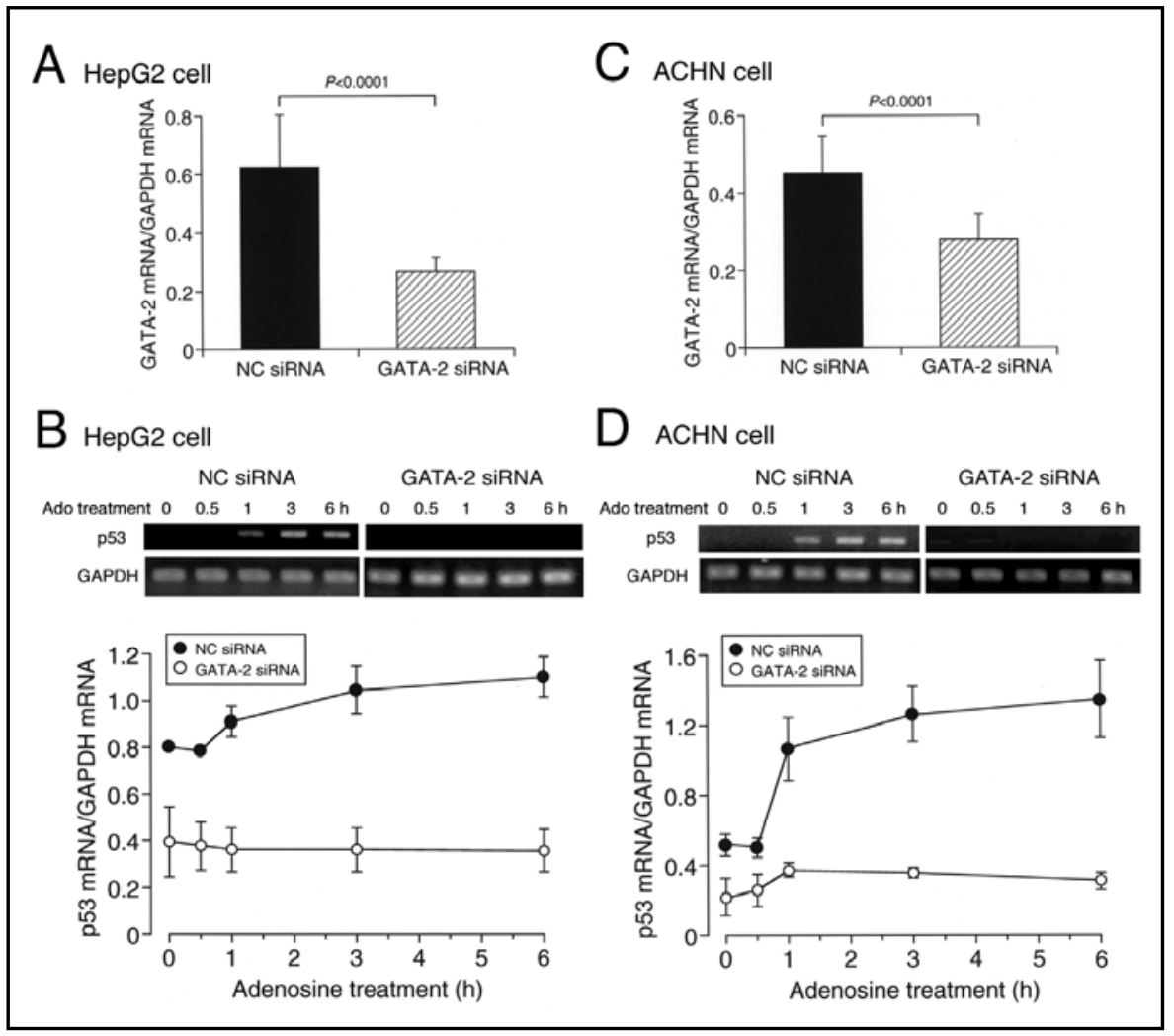
GAPDH mRNA. In the graph, each column represents the mean ( \pm SEM) relative expression of the GATA-2 mRNA against the GAPDH mRNA ( $\mathrm{n}=5$ independent experiments). $P$ value, unpaired $t$-test. (D) ACHN cells transfected with the NC siRNA or the GATA-2 siRNA were treated with adenosine $(3 \mathrm{mM})$ for periods of time as indicated, followed by RT-PCR. In the RT-PCR analysis, PCR products for the p53 mRNA were normalized by those for the GAPDH mRNA. In the graphs, each column represents the mean $( \pm$ SEM) relative expression of the p53 mRNA against the GAPDH mRNA ( $n=5$ independent experiments).

the p53 gene promoter. Expression of the GATA-2 mRNA in HepG2 cells were clearly suppressed for cells transfected with the GATA-2 siRNA (Fig. 9A). For HepG2 cells transfected with the NC siRNA, adenosine $(3 \mathrm{mM})$ increased expression of the p53 mRNA in a treatment time (0.5-6 h)-dependent manner (Fig. 9B). The adenosine effect was significantly prevented by silencing the GATA-2-targed gene $(P=0.0012$ as compared with expression of the p53 mRNA for cells transfected with the NC siRNA, ANOVA) (Fig. 9B). The question raised is whether GATA-2-mediated regulation of the p53 gene transcription is restricted in HepG2 cells alone. To address this question, we examined expression of the p53 mRNA in ACHN human renal cell adenocarcinoma cells. In the preliminary study, we have obtained the data that adenosine $(3 \mathrm{mM})$ induces ACHN cell apoptosis. Transfection with the GATA-2 siRNA into ACHN cells significantly reduced expression of the GATA-2 mRNA (Fig. 9C). Like for HepG2 cells, adenosine $(3 \mathrm{mM})$ increased expression of the p53 mRNA in $\mathrm{ACHN}$ cells in a treatment time (0.5-6 h)-dependent manner, and the effect was still inhibited by knockingdown GATA-2 (Fig. 9D) $(P<0.0001$ as compared with expression of the p53 mRNA for cells transfected with the NC siRNA, ANOVA). Overall, the results lead to a conclusion that adenosine stimulates p53 gene transcription through GATA-2 binding to the $\mathrm{p} 53$ promoter region from -240 to -146 to increase expression of $\mathrm{p} 53$ protein, responsible for adenosine-induced activation of caspase- $3,-8$, and -9 , to induced HepG2 cell apoptosis

\section{Discussion}

The results of the present study clearly demonstrate that extracellular adenosine induced HepG2 cell apoptosis in a p53-dependent manner. Of particular interest is that p53 is a transcriptional target of GATA-2 and that adenosine upregulates expression of the p53 mRNA and protein in HepG2 cells. Intriguingly, adenosine-induced upregulation of the p53 mRNA in a GATA-2-dependent manner was also found with ACHN cells. This implies

Yaguchi/Nakano/Gotoh/Nishizaki 
that GATA-2-regulated p53 gene transcription is not restricted in HepG2 cells alone but common for other cell types. In the present study, HepG2 cells were treated with adenosine at $3 \mathrm{mM}$ for $24 \mathrm{~h}$ to understand the mechanism underlying adenosine-induced HepG2 cell apoptosis. We have earlier found that adenosine induces HepG2 cell death in a concentration (0.1-20 mM)- and treatment time (24-72 h)-dependent manner [7]. This suggests that lower concentrations of adenosine could still induce HepG2 cell apoptosis by the mechanism similar to here. Adenosine receptors include $A_{1}, A_{2 a}, A_{2 b}$, and $A_{3}$ receptors. It remains unknown through what receptor adenosine promotes GATA-2-regulated p53 gene transcription to induce HepG2 cell apoptosis. Adenosineinduced HepG2 cell death was significantly inhibited by the $\mathrm{A}_{1}$ adenosine receptor inhibitor 8-CPT, the $\mathrm{A}_{2 \mathrm{a}}$ adenosine receptor inhibitor DMPX, the $\mathrm{A}_{2 \mathrm{~b}}$ adenosine receptor inhibitor MRS1706, and the $\mathrm{A}_{3}$ adenosine receptor inhibitor MRS1523 (unpublished data). This interprets that a specific adenosine receptor might not mediate adenosine-induced HepG2 cell apoptosis.

GATA-2 is a member of the GATA transcription factor family. GATA-2 plays a critical role in proper differentiation and function of erythroid cells [18, 19]. Lines of evidence have pointed to GATA-2 interaction with pituitary-specific positive transcription factor 1 , histone deacetylase 3, zinc finger and BTB domaincontaining protein 16 , LIM domain only 2 , promyelocytic leukemia protein, and Spi/PU.1 transcription factor [2429]. No direct evidence for GATA-2 interaction with $\mathrm{p} 53$, however, has not been provided, although there is a study suggesting the implication of p53 in GATA-2-dependent proliferation/survival of early hematopoietic cells and mast cell formation [23]. The present study is the first to provide direct evidence for GATA-2 binding to the p53 gene promoter to regulate $\mathrm{p} 53$ gene transcription.

p53 regulates cell cycling, DNA repair, and apoptosis through its transcriptional activity. Under the normal conditions, $\mathrm{p} 53$ forms a complex with $\mathrm{Mdm} 2$ or Mdmx, an E3 ubiquitin ligase [30, 31]. KAP-1 and 14-3-3-protein serve as a corepressor for Mdm2 and Mdmx, respectively. p53 is activated by DNA damage induced by a variety of factors that include UV light, ionizing radiation, chemical agents such as hydrogen peroxide, oxidative stress, osmotic shock, ribonucleotide depletion, and deregulated oncogene expression. DNA damage activates ataxia telangiectasia mutated (ATM) or AT- and Rad3-related (ATR), a protein kinase, which phosphorylates and activates checkpoint kinase 2 (Chk2) or Chk1, respectively. Activated ATM, on the other hand, phosphorylates p53 at Ser15,

GATA-2-Regulated p53 Gene Transcription dissociating $\mathrm{p} 53$ from a complex of p53/Mdm2 or Mdmx, and dissociated p53 is further phosphorylated at Ser20 by $\mathrm{Chk} 2$ or Chk1, to activate $\mathrm{p} 53$. Activated $\mathrm{p} 53$ promotes transcription of the $\mathrm{p} 21 / \mathrm{Waf} 1$ gene and the $\mathrm{p} 53 \mathrm{R} 2$ gene, and each protein arrests at the $\mathrm{G}_{1}$ phase of cell cycling by inhibiting cyclin-dependent kinase and repairs DNA damage, respectively $[32,33]$. In case of severe DNA damage, phosphorylated $\mathrm{p} 53$ at Ser 15 and Ser 20 is further phosphorylated at Ser46 by Ser46 kinase, which triggers transcription of the p53-regulated apoptosis-inducing protein 1 (p53AIP1) gene followed the Puma or Noxa genes [33]. The BH3-only Bcl-2 family Puma or Noxa dissociates $\mathrm{Bax} / \mathrm{Bak}$ from a complex with $\mathrm{Bcl}-2, \mathrm{Bcl}-\mathrm{X}_{\mathrm{L}}$, or Mcl-1, to induce apoptosis through mitochondrial damage $[11,12]$. For another pathway, Puma or Noxa induces apoptosis by neutralizing function of Bcl-2, Bcl$\mathrm{X}_{\mathrm{L}}$, or Mcl-1 through its direct binding [13].

p53 can also induce apoptosis in a transcriptionindependent manner [14-17]. p53 directly binds to proapoptotic Bcl-2-family proteins, leading to efflux of cytochrome $\mathrm{c}$ and Smac/DIABLO from the mitochondria. Cytochrome $\mathrm{c}$ forms a complex with Apaf-1 and caspase9, thereby activating caspase-9 and the effector caspase3 to induce apoptosis. Smac/DIABLO indirectly activates caspase- 3 by inhibiting IAPs, to induce apoptosis.

In the present study, adenosine activated caspase$3,-8$, and -9 in HepG2 cells, and the effect was prevented by knocking-down $\mathrm{p} 53$. This accounts for the implication of p53 in adenosine-induced HepG2 cell apoptosis. The question addressing is whether activation of those caspases is $\mathrm{p} 53$ transcription-dependent or -independent. We have obtained the data that adenosine downregulates expression of the $\mathrm{Bcl}-\mathrm{X}_{\mathrm{L}} \mathrm{mRNA}$ and protein but otherwise upregulates expression of the Bid mRNA and protein in HepG2 cells through $\mathrm{A}_{2 \mathrm{a}}$ adenosine receptors, without affecting mRNA and protein expression of Bcl-2, Bad, and Bax (unpublished data). This may interpret the p53 transcription-dependent effect in adenosine-induced HepG2 cell apoptosis. In further support of this note, adenosine upregulated expression of mRNAs for TNF, TRADD, TRAIL-R2, RIPK1, FADD, and caspase-9 in HepG2 cells [7]. No direct evidence for p53-mediated transcription of those apoptosis-related genes has not been provided as of yet. In addition, the regulatory pathway underlying p53 gene transcription through GATA-2 is presently far from understanding. To address these questions, we are currently carrying out further experiments.

In conclusion, the results of the present study show that adenosine promotes GATA-2-regulated p53 gene 
transcription and induces HepG2 cell apoptosis by activating caspase-3, -8 , and -9 in a p53-dependent manner. This may represent fresh insight into the molecular pathway underlying adenosine-induced HepG2 cell apoptosis.

\section{References}

Saitoh M, Nagai K, Nakagawa K, Yamamura T, Yamamoto S, Nishizaki T: Adenosine induces apoptosis in the human gastric cancer cells via an intrinsic pathway relevant to activation of AMPactivated protein kinase. Biochem Pharmacol 2004;67:2005-2011.

Yasuda Y, Saito M, Yamamura T, Yaguchi T, Nishizaki T: Extracellular adenosine induces apoptosis in Caco-2 human colonic cancer cells by activating caspase-9/-3 via $A_{2 a}$ adenosine receptors. J Gastroenterol 2009;44:56-65.

Sai K, Yang D, Yamamoto H, Yamamoto H, Fujikawa H, Yamamoto S, Nagata T, Saito M, Yamamura T, Nishizaki T: $A_{1}$ adenosine receptor signal and AMPK involving caspase-9/-3 activation are responsible for adenosine-induced RCR1 astrocytoma cell death. Neurotoxicol 2006;27:458-467.

Bar-Yehuda S, Stemmer SM, Madi L, Castel D, Ochaion A, Cohen S, Barer F, Zabutti A, Perez-Liz G, Del Valle L, Fishman P: The $\mathrm{A}_{3}$ adenosine receptor agonist CF102 induces apoptosis of hepatocellular carcinoma via deregulation of the Wnt and $\mathrm{NF}-\kappa \mathrm{B}$ signal transduction pathways. Int $\mathrm{J}$ Oncol 2008;33:287-295.

$\checkmark 5$ Yang D, Yaguchi T, Yamamoto H, Nishizaki T: Intracellularly transported adenosine induces apoptosis in $\mathrm{HuH}-7$ human hepatoma cells by downregulating c-FLIP expression causing caspase-3/-8 activation Biochem Pharmacol 2007;73:1665-1675.

-6 Yang D, Yaguchi T, Nakano T, Nishizaki $\mathrm{T}$ : Adenosine-induced caspase-3 activation by tuning $\mathrm{Bcl}-\mathrm{X}_{\mathrm{L}} / \mathrm{DIABLO} /$ IAP expression in $\mathrm{HuH}-7$ human hepatoma cells. Cell Biol Toxicol 2010;26:319-330.

-7 Yang D, Yaguchi T, Lim C-R, Ishizawa Y, Nakano T, Nishizaki T: Tuning of apoptosis-mediator gene transcription in HepG2 human hepatoma cells through an adenosine signal. Cancer Lett 2010;29:225-229.

-8 Earnshaw WC, Martins LM, Kaufmann SH: Mammalian caspases: structure, activation, substrates, and functions during apoptosis. Annu Rev Biochem 1999;68:383-424.
Micheau O, Tschopp J: Induction of TNF receptor I-mediated apoptosis via two sequential signaling complexes. Cell 2003;114:181-190.

10 Schuler M, Green DR. Mechanisms of p53-dependent apoptosis. Biochem Soc Trans 2001;29:684-688.

11 Yee KS, Vousden KH: Complicating the complexity of p53. Carcinogenesis 2005;26:1317-1322.

12 Ploner C, Kofler R, Villunger A: Noxa: at the tip of the balance between life and death. Oncogene 2008;27:S84-92.

13 Yee KS, Vousden KH: Contribution of membrane localization to the apoptotic activity of PUMA. Apoptosis 26 2008;13:87-95.

14 Galluzzi L, Morselli E, Kepp O, Tajeddine N, Kroemer G: Targeting p53 to mitochondria for cancer therapy. Cell Cycle 2008;7:1949-1955.

15 Moll UM, Wolff S, Speidel D, Deppert 27 W: Transcription-independent proapoptotic functions of p53. Curr Opin Cell Biol 2005;17:631-636.

16 Schuler M, Green DR: Mechanisms of 28 p53-dependent apoptosis. Biochem Soc Trans 2001;29:684-688.

17 Speidel D: Transcription-independent p53 apoptosis: an alternative route to death. Trends Cell Biol 2010;20:14-24.

18 Kaneko H, Shimizu R, Yamamoto M: GATA factor switching during erythroid $>29$ differentiation. Curr Opin Hematol 2010;17:163-168.

$\checkmark 19$ Bresnick EH, Lee HY, Fujiwara T, Johnson KD, Keles S: GATA switches as developmental drivers. J Biol Chem 2010;285:31087-31093.

20 Hosoya T, Maillard I, Engel JD: From the cradle to the grave: activities of GATA-3 throughout T-cell development and differentiation. Immunol Rev 2010;238:110-125.

21 Chou J, Provot S, Werb Z: GATA3 in $>$ development and cancer differentiation: cells GATA have it! J Cell Physiol 2010;222:42-49.

-22 Trainor CD, Mas C, Archambault P, Di Lello P, Omichinski JG: GATA-1 associates with and inhibits p53. Blood 2009; 114:165-173.

23 Tsai FY, Orkin SH: Transcription factor GATA-2 is required for proliferation/ survival of early hematopoietic cells and mast cell formation, but not for erythroid and myeloid terminal differentiation. Blood 1997;89:3636-3643.
Osamura RY, Egashira N, Kajiya H, Takei M, Tobita M, Miyakoshi T, Inomoto C, Takekoshi S, Teramoto A: Pathology, pathogenesis and therapy of growth hormone $(\mathrm{GH})$-producing pituitary adenomas: technical advances in histochemistry and their contribution. Acta Histochem Cytochem 2009;42:95104.

Ozawa $\mathrm{Y}$, Towatari M, Tsuzuki S, Hayakawa F, Maeda T, Miyata Y, Tanimoto $\mathrm{M}$, Saito $\mathrm{H}$ : Histone deacetylase 3 associates with and represses the transcription factor GATA2. Blood 2001;98:2116-2123.

Tsuzuki S, Enver T: Interactions of GATA-2 with the promyelocytic leukemia zinc finger (PLZF) protein, its homologue FAZF, and the $\mathrm{t}(11 ; 17)$ generated PLZF-retinoic acid receptor $\alpha$ oncoprotein. Blood 2002;99:3404-410. Herberth B, Minkó K, Csillag A, Jaffredo T, Madarász E: SCL, GATA-2 and Lmo2 expression in neurogenesis. Int $\mathrm{J}$ Dev Neurosci 2005;23:449-463.

Tsuzuki S, Towatari M, Saito H, Enver T: Potentiation of GATA-2 activity through interactions with the promyelocytic leukemia protein (PML) and the $t(15 ; 17)$-generated PMLretinoic acid receptor alpha oncoprotein. Mol Cell Biol 2000;20:6276-6286.

Zhang P, Behre G, Pan J, Iwama A, WaraAswapati N, Radomska HS, Auron PE, Tenen DG, Sun Z: Negative cross-talk between hematopoietic regulators: GATA proteins repress PU.1. Proc Natl Acad Sci USA 1999;96:8705-8710.

$\checkmark 30$ Meulmeester E, Pereg Y, Shiloh Y, Jochemsen AG: ATM-mediated phosphorylations inhibit $\mathrm{Mdmx} / \mathrm{Mdm} 2$ stabilization by HAUSP in favor of p53 activation. Cell Cycle 2005;4:11661170 .

Cho YJ, Liang P: S-phase-coupled apoptosis in tumor suppression. Cell Mol Life Sci 2011;68:1883-1896.

-32 Jung YS, Qian Y, Chen X: Examination of the expanding pathways for the regulation of $\mathrm{p} 21$ expression and activity. Cell Signal 2010;22:1003-1012.

Nakamura Y: Isolation of p53-target genes and their functional analysis. Cancer Sci 2004;95:7-11. 